\title{
Electronic Medical Records in a Mass-Casualty Exercise
}

\author{
Ahmad Fayaz-Bakhsh, MD PhD; ${ }^{1}$ Mehrab Sharifi-Sedeh ${ }^{2}$
}

1. Tehran University of Medical Sciences, School of Allied Medical Sciences, Department of Healthcare Management, Tehran, Iran

2. Tehran University of Medical Sciences, School of Public Health, Department of Disaster Management, Tehran, Iran

\section{Correspondence:}

Ahmad Fayaz-Bakhsh, MD, PhD

Tehran University of Medical Sciences

School of Medicine

P.O. Box 14155-6447

1417613151

Tehran, Iran

E-mail: fayaz@tums.ac.ir

Received: July 3, 2013

Accepted: August 18, 2013

Online publication: November 6, 2013

doi:10.1017/S1049023X13009047
The following comments are in reference to the article "Impact of wireless electronic medical record system on the quality of patient documentation by emergency field responders during a disaster mass-casualty exercise."

1. Wireless Internet Information System for Medical Response to Disasters (WIISARD) is a good system with respect to being rapidly deployable and scalable at a mass-casualty incident site, but there is a need for educated personnel and many devices and equipment. In a disaster, we need equipment that must be characterized by a number of critical functionalities:

- Simple in use and requiring minimal field maintenance;

- Operable by personnel who are unskilled in advanced telecommunications;

- Rugged enough to permit all-weather, rapid tactical ground/vertical deployment with non-specialized, locally available means (such as light-haul trucks/light-lift helicopters);

- Multimedia (data/voice/video) capable;

- Capable of sustaining heavy, bi-directional, multi-channel traffic (high bandwidth capability and bandwidth redundancy). ${ }^{2}$ Many interactive medical devices are less easy to use than they might be.

2. It would have been better if the WIISARD system had been implemented in a real disaster or a large-scale disaster exercise.

3. In many countries, rescuers, first responders, and incident managers often must provide care to overwhelming numbers of victims, with limited resources, minimal information and inadequate communication tools. ${ }^{3}$ The WIISARD system, however, needs highly-educated personnel and advanced equipment.

4. Among the most typical consequences of disasters is the near or complete collapse of terrestrial telecommunications infrastructures. ${ }^{4}$ Internet connectivity may be very difficult for disaster managers. Also, post-disaster telecommunications difficulties are not restricted to wired/fixed networks but affect the wireless ones just as intensely: after a short radio path, wireless communication systems eventually connect to a ground segment through an access point. ${ }^{4}$

References

1. Chan TC, Griswold WG, Buono C, et al. Impact of wireless electronic medical record system on the quality of patient documentation by emergency field responders during a disaster mass-casualty exercise. Prehosp Disaster Med. 2011; 26(4):268-275.

2. Patricelli F, Beakley JE, Carnevale A, Tarabochia M, von Lubitz DK. Disaster management and mitigation: the telecommunications infrastructure. Disasters. 2009;33(1):23-37.

3. Chan TC, Buono CJ, Killeen JP, Griswold WG, Huang R, Lenert L. Tablet computing for disaster scene managers. Presented at: AMIA Annual Symposium Proceedings 2006.

4. Iannella R, Henricksen K. Managing information in the disaster coordination centre: lessons and opportunities. Presented at: 4th International Conference on Information Systems for Crisis Response and Management (ISCRAM); May 13-16, 2007; Delft, Netherlands. 


\section{Author reply:}

\section{Theodore C. Chan, MD; ${ }^{1}$ William G. Griswold, $\mathrm{PhD} ;{ }^{2}$ James P. Killeen, $\mathrm{MD}^{1}$}

1. Department of Emergency Medicine, University of California, San Diego, San Diego, California USA

2. Department of Computer Science and Engineering, University of California, San Diego, San Diego, California USA

\section{Correspondence:}

Theodore Chan, MD

UCSD DEM

200 West Arbor Drive \#8676

San Diego, California 92103 USA

E-mail: tcchan@ucsd.edu
We thank Drs. Fayaz-Bakhsh and Sharifi-Sedeh for their interest in our article on WIISARD. The NIH-funded study, in fact, was designed to begin testing technologies and solutions to the very questions and concerns they raise in regards to disaster response.

1. We agree wholeheartedly with the need for a rapidly-deployable and scalable bidirectional information and communication system for mass-casualty incidents (MCIs) that is rugged, reliable and redundant, and simple to use by personnel. In fact, the WIISARD project was intended to begin testing new technologies in the field setting with that very goal in mind.

2. We agree that it is better to test such technologies and systems in large-scale MCI exercises as we did with WIISARD.

3. Adoption of any new technology requires education and personnel who have familiarity with such systems. The focus of WIISARD was to design systems that replicated and improved current workflows for personnel during MCIs. Incident command systems for MCIs now include a specific logistic officer to manage and direct all logistics issues during disaster responses. We suspect, with the ubiquity of technology in society in general, that there will be a need for technology-proficient leaders and staff also participating in disaster responses in the future.

4. We agree that loss of conventional telecommunications infrastructure at disaster sites is a concern. In fact, the WIISARD team recognized this as a concern and implemented various technologies to address those concerns including the use of an ad hoc field network and ABC (always best connected) systems that could circumvent challenges around damaged or overwhelmed traditional communication network systems.

Again, we thank Drs. Fayaz-Bakhsh and Sharifi-Sedeh for their comments on our work. 